\title{
Perfil lipídico da carne de frangos de corte de diferentes cruzamentos criados em sistema alternativo
}

\author{
[Lipid profile of broiler meat from different crosses raised in alternative system] \\ F.L. Cruz, P.B. Faria \\ F.L. Cruz \\ https://orcid.org/0000-0002-5353-9347 \\ P.B. Faria \\ https://orcid.org/0000-0002-2890-5472
}

Universidade Federal de Lavras - Lavras, MG

\begin{abstract}
RESUMO
Objetivou-se avaliar o perfil lipídico da carne de frangos de diferentes genótipos. O delineamento foi inteiramente ao acaso (DIC), disposto em esquema fatorial (5x2), sendo cinco genótipos (New Hampshire - NHS; Gigante Negra de Jersey - GNJ; Índio Gigante - IG; cruzamento entre as raças IG e NHS - IG x NHS; e entre as raças IG e GNJ - IG x GNJ) e dois sexos, com cinco repetições, sendo cada uma representada por três aves, totalizando 150 aves, abatidas aos 105 dias. As análises de perfil lipídico foram realizadas no peito e na coxa. Foram calculadas as estimativas das atividades enzimáticas, os índices de aterogenicidade e de trombogenicidade. Os genótipos IG e IG x NHS apresentaram maiores teores de ácido araquidônico e DHA. Foram observados maiores teores de ácidos graxos saturados e monoinsaturados no peito para os genótipos IG x NHS e NHS, respectivamente. Maiores médias de ácidos graxos poli-insaturados e ômega 3 foram observadas para os genótipos IG e IG x NHS. O genótipo IG x NHS e as fêmeas apresentaram melhores características de qualidade de carne, por oferecerem uma maior fonte de ômega 3 .
\end{abstract}

Palavras-chave: aves, Índio Gigante, ácidos graxos, ômega 3, atividades enzimáticas

\begin{abstract}
The objective was to evaluate the lipid profile of chickens from different genotypes. The design was completely randomized arranged in factorial scheme (5x2), being 5 genotypes (New Hampshire - NHS, Gigante Negra de Jersey - GNJ, Índio Gigante - IG; poultry from the cross between IG and NHS breeds $I G \times N H S$ and between IG and GNJ breeds - IG $x$ GNJ) and two genders, with five replicates and three poultry per replicate, totaling 150 birds, slaughtered at 105 days. Lipid profile analyzes were performed on the breast and thigh. Estimates of the enzymatic activities related to lipid metabolism were calculated, in addition to the atherogenicity and thrombogenicity indexes. The IG and IG $x$ NHS genotypes showed higher levels of arachidonic acid and DHA. Higher levels of saturated and monounsaturated fatty acids were observed in the breast for $I G \times N H S$ and NHS genotypes, respectively. Higher averages of polyunsaturated fatty acids and omega 3 were observed for the $I G$ and $I G \times N H S$ genotypes. The genotype IG $x$ NHS and the females presented better characteristics of meat quality, for offering a greater source of omega 3.
\end{abstract}

Keywords: poultry, índio gigante, fatty acids, omega 3, enzymatic activities

\section{INTRODUÇÃO}

Devido à evolução dos meios de comunicação, o consumidor moderno tem se preocupado cada vez mais com a sua alimentação, atentando-se para a qualidade, a composição nutricional dos alimentos e seus efeitos na saúde humana.

Recebido em 4 de julho de 2017

Aceito em 22 de maio de 2018

E-mail: fabiolourescruz@gmail.com
Os lipídeos são nutrientes essenciais à dieta humana, sendo indispensável para a realização de funções específicas do metabolismo (French et al., 2000). No entanto, os efeitos dos lipídeos na saúde humana dependem do seu perfil de ácidos graxos, podendo ser benéficos ou maléficos. Nesse contexto, a carne de frango tem seu consumo aumentado por ser considerada de melhor 
qualidade devido ao menor teor de gorduras saturadas em relação às carnes vermelhas (Nascif $e t$ al., 2004).

Vários fatores podem alterar o perfil de ácidos graxos, como a nutrição, a genética, o sistema de criação, o sexo e a idade de abate das aves (Lara et al., 2006; Ribeiro et al., 2008). No entanto, os efeitos sobre o perfil de ácidos graxos da carne relacionados às características genéticas de frangos são pouco estudados, principalmente no que diz respeito às raças que atualmente são utilizadas para a criação semi-intensiva ou extensiva e ao efeito de sexo. Entre os diferentes genótipos comerciais, destacam-se as aves da raça New Hampshire, as quais apresentam boas características para a produção de carne, podem ser utilizadas em diversos cruzamentos e originaram muitos híbridos comercias de corte de uso atual, assim como as aves da raça Gigante Negra de Jersey, que apresentam maior porte e aptidão para a produção de carne (Albino et al., 2014). Por outro lado, uma raça recente que tem aumentado entre os criadores são as aves Índio Gigante, que, embora ornamentais, são utilizadas para produção de carne devido ao seu maior porte, apesar da menor precocidade (ABCIG, 2016).

Assim, objetivou-se avaliar o perfil lipídico da carne de frangos de corte de diferentes raças, cruzamentos e sexo, criados em sistema alternativo.

\section{MATERIAL E MÉTODOS}

O estudo foi realizado por meio de delineamento experimental inteiramente ao acaso (DIC), disposto em esquema fatorial $(5 \times 2)$, sendo cinco genótipos (Índio Gigante - IG, New Hampshire - NHS, Gigante Negra de Jersey GNJ, geração F1 resultante do cruzamento entre galos da raça Índio Gigante e galinhas da raça New Hampshire - IG x NHS, geração F1 resultante do cruzamento entre galos da raça Índio Gigante e galinhas da raça Gigante Negra de Jersey - IG x GNJ) e dois sexos (macho e fêmea), totalizando 10 tratamentos. Cada tratamento foi composto por cinco repetições, sendo cada repetição representada por três aves, totalizando 15 aves por tratamento. Dessa forma, foram utilizadas 150 aves em todo o experimento. Todos os procedimentos descritos foram aprovados pela Comissão de Ética no Uso de
Animais (Ceua) da Universidade Federal de Lavras ( $\mathrm{n}^{\mathrm{o}}$ protocolo $017 / 14$ ).

A dieta para os frangos de corte tipo caipira foi composta de três formulações de rações (Tab. 1), de acordo com a fase de criação, que foi estabelecida conforme a idade da ave em dias. A dieta foi formulada com base nas recomendações para frangos tipo caipira da Fundación Española para el Desarrollo de la Nutrición Animal (Necessidades..., 2008) e na tabela de composição dos alimentos, segundo Rostagno et al. (2011). As aves foram criadas em três fases: inicial (um a 30 dias), criadas em galpão de alvenaria, com ração e água ad libitum, sem acesso à área de pastejo; fase de crescimento (31 a 55 dias) e final (56 a 105 dias), criadas em área experimental com acesso ao pastejo, ração e água ad libitum; em cada unidade experimental, com área de $90 \mathrm{~m}^{2}$, foram alojadas 30 aves do mesmo genótipo, sendo 15 de cada sexo, obtendo-se, dessa forma, uma densidade de uma ave para cada $3 \mathrm{~m}^{2}$ de área (Brasil, 1999). Em todas as fases de criação, não foram utilizados programas de luz. As áreas de pastagens, em cada unidade experimental, foram formadas com a gramínea Tifton 85 (Cynodon spp.)

Aos 105 dias de idade, as aves foram pesadas, identificadas e mantidas em jejum por oito horas. Após esse período, foram abatidas por deslocamento cervical seguido de sangria, respeitando-se o método humanitário de abate. As amostras para a determinação da composição lipídica foram extraídas das partes musculares dos cortes de peito e da coxa, isentas de pele, de acordo com metodologia de Folch et al. (1957). A esterificação para determinação da composição em ácidos graxos foi feita segundo metodologia de Hartman e Lago (1973). Em seguida, as amostras foram submetidas à cromatografia gasosa para a determinação do perfil de ácidos graxos. Para isso, foi utilizada uma coluna capilar de sílica fundida de $100 \mathrm{~m}$ de comprimento, diâmetro de $0,25 \mathrm{~mm}$ e $0,2 \mu \mathrm{m}$ de espessura do filme Supelco (SP-2560, Bellefonte, $P A, U S)$. A identificação e a quantificação dos ácidos graxos foram realizadas de acordo com o padrão Supelco 37 (Fame Mix).

Foram calculados os índices de atividades das enzimas $\Delta 9$-dessaturase ${ }^{\mathrm{C} 16}, \Delta 9$-dessaturase $\mathrm{C}^{\mathrm{C} 18}$, elongase $^{\mathrm{C16}-\mathrm{C} 18}$ e de tioesterase ${ }^{\mathrm{C16}-14}$, de acordo com metodologia de Metz et al. (2009), em que: 
índice de atividade de $\Delta 9$-dessaturase ${ }^{\mathrm{C} 16}=100$ [(C16:1) / (C16:1 + C16:0)]; índice de atividade de $\Delta 9$-dessaturase $\mathrm{C}^{\mathrm{C} 18}=100[(\mathrm{C} 18: 1 \omega 9 \mathrm{c}) /(\mathrm{C} 18: 1 \omega 9 \mathrm{c}+$ $\mathrm{C} 18: 0)]$; índice de atividade de elongase ${ }^{\mathrm{C} 16-\mathrm{C} 18}=100$
$[(\mathrm{C} 18: 0+\mathrm{C} 18: 1 \omega 9 \mathrm{c}) /(\mathrm{C} 16: 0+\mathrm{C} 16: 1+\mathrm{C} 18: 0+$ $\mathrm{C} 18: 1 \omega 9 \mathrm{c})]$; e índice de atividade de tioesterase ${ }^{\mathrm{C} 16-\mathrm{C} 14}$ $=100[(\mathrm{C} 16: 0) /(\mathrm{C} 16: 0+\mathrm{C} 14: 0)]$.

Tabela 1. Composições e valores calculados das rações experimentais para frangos de corte tipo caipira, de acordo com a fase de criação e a faixa de idade em dias

\begin{tabular}{|c|c|c|c|}
\hline Ingrediente $(\mathrm{kg})$ & $\begin{array}{c}\text { Inicial (um a } 30 \\
\text { dias) }\end{array}$ & Crescimento (31 a 55 dias) & $\begin{array}{c}\text { Final (56 a } 105 \\
\text { dias) }\end{array}$ \\
\hline Milho & 57,91 & 63,69 & 68,54 \\
\hline Farelo de soja & 31,48 & 25,94 & 24,03 \\
\hline Farelo de trigo & 6,81 & 7,01 & 4,23 \\
\hline Fósfato bicálcico & 1,59 & 1,36 & 1,31 \\
\hline Calcário & 1,35 & 1,26 & 1,18 \\
\hline Sal comum & 0,38 & 0,35 & 0,33 \\
\hline Premix mineral $^{1}$ & 0,10 & 0,10 & 0,10 \\
\hline Premix vitamínico $^{2}$ & 0,10 & 0,10 & 0,10 \\
\hline DL-metionina $99 \%$ & 0,20 & 0,14 & 0,13 \\
\hline L-lisina $78 \%$ & 0,03 & & \\
\hline Cloreto de colina $60 \%$ & 0,05 & 0,05 & 0,05 \\
\hline Total $(\mathrm{kg})$ & 100 & 100 & 100 \\
\hline \multicolumn{4}{|l|}{ Valores calculados } \\
\hline Proteína bruta $(\%)$ & 20,00 & 18,00 & 17,00 \\
\hline $\mathrm{EM}^{3}(\mathrm{kcal} / \mathrm{kg})$ & 2800 & 2870 & 2940 \\
\hline Cálcio $(\%)$ & 1,00 & 0,90 & 0,85 \\
\hline Fósforo disponível (\%) & 0,42 & 0,37 & 0,35 \\
\hline Sódio $(\%)$ & 0,17 & 0,16 & 0,15 \\
\hline $\mathrm{M}+\mathrm{C}$ dig. ${ }^{4}(\%)$ & 0,74 & 0,64 & 0,61 \\
\hline Lisina digestível (\%) & 0,96 & 0,81 & 0,76 \\
\hline Triptofano digestível (\%) & 0,22 & 0,19 & 0,18 \\
\hline Fibra bruta $(\%)$ & 3,32 & 3,14 & 2,86 \\
\hline
\end{tabular}

${ }^{\mathrm{l}}$ Premix mineral: manganês $75000 \mathrm{mg}$, zinco $70000 \mathrm{mg}$, ferro $50000 \mathrm{mg}$, cobre $8500 \mathrm{mg}$, iodo $1500 \mathrm{mg}$, cobalto $200 \mathrm{mg}$. ${ }^{2}$ Premix vitamínico: vitamina A $7000000 \mathrm{UI}$, vitamina $\mathrm{D}_{3} 2100000 \mathrm{UI}$, vitamina E 50000mg, vitamina $\mathrm{K}_{3} 2000 \mathrm{mg}$, vitamina $B_{1} 2000 \mathrm{mg}$, vitamina $B_{2} 4000 \mathrm{mg}$, vitamina $B_{6} 3000 \mathrm{mg}$, vitamina $B_{12} 3000 \mathrm{mg}$, niacina $39800 \mathrm{mg}$, ácido pantotênico $15620 \mathrm{mg}$, ácido fólico $1000 \mathrm{mg}$, selênio $200 \mathrm{mg}$, biotina $100 \mathrm{mg}$, antioxidante $100000 \mathrm{mg}$. ${ }^{3} \mathrm{EM}$ : energia metabolizável; ${ }^{4} \mathrm{M}+$ $\mathrm{C}$ dig.: metionina mais cistina digestível.

Foram determinados também os índices de aterogenicidade e de trombogenicidade de acordo com metodologia de Ulbricht e Southgate (1991), em que: índice de aterogenicidade $=[4$ $(\mathrm{C} 14: 0)+\mathrm{C} 16: 0] /(\mathrm{SAT}+\mathrm{POL})$ e índice de trombogenicidade $=(\mathrm{C} 14: 0+\mathrm{C} 16: 0+\mathrm{C} 18: 0) /[(0,5$ $\mathrm{x} \mathrm{MON})+(0,5 \times \Sigma \omega 6)+(3 \times \Sigma \omega 3)+(\Sigma \omega 3 / \Sigma \omega 6)]$.

Os dados foram analisados com apoio do programa estatístico SISVAR ${ }^{\circledR}$ (Ferreira, 2000). As variáveis com respostas de efeitos significativos na análise de variância para os tratamentos e/ou interações foram submetidas ao teste de comparação de médias (teste de Tukey) $(\alpha=5 \%)$.

\section{RESULTADOS E DISCUSSÃO}

Houve influência do sexo sobre os teores de C10:0 do peito apenas para as aves da raça New
Hampshire (NHS), que apresentaram os maiores valores para os machos (Tab. 2), enquanto para as aves do cruzamento IG x GNJ, foi verificada média superior desse ácido graxo para as fêmeas.

Para os teores de C11:0 do peito, diferenças entre sexos ocorreram apenas entre aves da raça New Hampshire (NHS), que se destacaram pela maior média, da mesma forma que os machos deste grupo genético (Tab. 2). As fêmeas da raça Gigante Negra de Jersey (GNJ) apresentaram

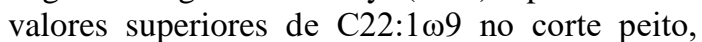
enquanto no cruzamento IG $\mathrm{x}$ GNJ ocorreu resultado inverso com maiores médias para os machos. Entre os machos, as aves resultantes do cruzamento IG x NHS e IG x GNJ apresentaram maiores teores de C22:1 $\omega 9$, e entre as fêmeas, as aves IG $\mathrm{x}$ NHS apresentaram as maiores quantidades. 
Tabela 2. Perfil de ácidos graxos do peito de frangos de corte criados em sistema alternativo

\begin{tabular}{|c|c|c|c|c|c|c|c|c|c|c|}
\hline \multirow{2}{*}{$\begin{array}{c}\text { Variável } \\
\text { Ácido graxo }\end{array}$} & \multicolumn{5}{|c|}{ Genótipo (G) } & \multicolumn{2}{|c|}{$\operatorname{Sexo}(\mathrm{S})$} & \multicolumn{3}{|c|}{$\mathrm{P}^{1}$} \\
\hline & NHS & GNJ & IG & IG x NHS & IG x GNJ & Macho & Fêmea & G & $\mathrm{S}$ & GxS \\
\hline & $0,20 \mathrm{aA}$ & $0,11 \mathrm{aAB}$ & $0,05 \mathrm{aB}$ & $0,040 \mathrm{aB}$ & $0,03 \mathrm{bB}$ & 0,09 & - & & & \\
\hline \multirow[t]{3}{*}{ C10:0 } & $0,08 \mathrm{bA}$ & $0,04 \mathrm{aA}$ & $0,14 \mathrm{aA}$ & $0,03 \mathrm{aA}$ & $0,16 \mathrm{aA}$ & - & 0,09 & 0,088 & 0,947 & 0,009 \\
\hline & 0,14 & 0,07 & 0,10 & 0,03 & 0,10 & - & - & & & \\
\hline & $0,20 \mathrm{aA}$ & $0,01 \mathrm{aB}$ & $0,01 \mathrm{aB}$ & $0,00 \mathrm{aB}$ & $0,00 \mathrm{aB}$ & 0,04 & - & & & \\
\hline \multirow[t]{2}{*}{ C11:0 } & $0,02 \mathrm{bA}$ & $0,00 \mathrm{aA}$ & $0,00 \mathrm{aA}$ & $0,10 \mathrm{aA}$ & $0,06 \mathrm{aA}$ & - & 0,04 & 0,161 & 0,736 & 0,039 \\
\hline & 0,11 & 0,01 & 0,01 & 0,05 & 0,03 & - & - & & & \\
\hline C12:0 & $0,09 \mathrm{~B}$ & $0,17 \mathrm{AB}$ & $0,12 \mathrm{~B}$ & $0,41 \mathrm{~A}$ & $0,11 \mathrm{~B}$ & 0,18 & 0,18 & 0,003 & 0,918 & 0,127 \\
\hline $\mathrm{C} 14: 0$ & 0,68 & 0,78 & 0,73 & & & 0,94 & 0,73 & 0,172 & 0,133 & 0,424 \\
\hline C14:1 & 0,06 & 0,06 & 0,04 & 0 & 0 , & 0,05 & 0,05 & 0,469 & 0,791 & 0,553 \\
\hline C15:0 & 0,21 & 0,25 & 0,27 & 0,24 & 0,25 & $0,29 \mathrm{~A}$ & $0,19 \mathrm{~B}$ & 0,871 & 0,012 & 0,612 \\
\hline C16:0 & $23,57 \mathrm{AB}$ & $22,52 \mathrm{~B}$ & $22,60 \mathrm{AB}$ & $23,38 \mathrm{AB}$ & $23,66 \mathrm{~A}$ & 23,19 & 23,10 & 0,011 & 0,711 & 0,220 \\
\hline C16:1 & $2,59 \mathrm{~A}$ & $2,11 \mathrm{AB}$ & $1,37 \mathrm{BC}$ & $1,11 \mathrm{C}$ & $1,70 \mathrm{BC}$ & 1,78 & 1,78 & 0,001 & 0,993 & 0,445 \\
\hline C17:0 & 0,48 & 0,51 & 0,56 & 0,46 & 0,52 & $0,59 \mathrm{~A}$ & $0,42 \mathrm{~B}$ & 0,936 & 0,033 & 0,649 \\
\hline C17:1 & 0,68 & 0,49 & 0,52 & 0,48 & 0,70 & 0,58 & 0,57 & 0,474 & 0,975 & 0,072 \\
\hline C18:0 & $10,54 \mathrm{~B}$ & $10,99 \mathrm{AB}$ & $12,13 \mathrm{AB}$ & $12,44 \mathrm{~A}$ & $11,53 \mathrm{AB}$ & 11,71 & 11,34 & 0,019 & 0,349 & 0,932 \\
\hline $\mathrm{C} 18: 1 \omega 9 \mathrm{t}$ & 0,67 & 0,65 & 1,03 & 0,92 & 0,75 & 1,05 & 0,59 & 0,731 & 0,065 & 0,214 \\
\hline $\mathrm{C} 18: 1 \omega 9 \mathrm{c}$ & $32,77 \mathrm{~A}$ & $30,99 \mathrm{AB}$ & $27,98 \mathrm{BC}$ & $26,48 \mathrm{C}$ & $28,97 \mathrm{BC}$ & 29,21 & 29,66 & 0,001 & 0,564 & 0,357 \\
\hline $\mathrm{C} 18: 2 \omega 6 \mathrm{c}$ & 19,00 & 19,63 & 17,57 & 17,76 & 18,84 & 18,41 & 18,71 & 0,174 & 0,618 & 0,792 \\
\hline C20:0 & 0,06 & 0,07 & 0,07 & 0,07 & 0,09 & 0,08 & 0,07 & 0,191 & 0,120 & 0,334 \\
\hline $\mathrm{C} 18: 3 \omega 6$ & $0,08 \mathrm{AB}$ & $0,09 \mathrm{~A}$ & $0,04 \mathrm{~B}$ & $0,05 \mathrm{AB}$ & $0,06 \mathrm{AB}$ & 0,07 & 0,06 & 0,012 & 0,424 & 0,993 \\
\hline$C: 20: 1$ & 0,15 & 0,17 & 0,15 & & 0,16 & 0,16 & 0,15 & 0,470 & 0,412 & 0,458 \\
\hline $\mathrm{C} 18: 3 \omega$ & 0,43 & 0,77 & 0,68 & & 0,7 & 0,77 & 0,61 & 0,571 & 0,351 & 0,119 \\
\hline C20:2 & 0,24 & 0,28 & 0,31 & & 0, & 0,31 & 0,27 & 0,119 & 0,131 & 0,251 \\
\hline C22:0 & 0, & 0,1 & 0,1 & & 0, & $0,08 \mathrm{~B}$ & $0,11 \mathrm{~A}$ & 0,248 & 0,019 & 0,670 \\
\hline \multirow[t]{2}{*}{$\mathrm{C} 20: 3 \omega 6$} & 0,48 & 0,6 & 0,54 & & 0 , & $0,52 \mathrm{~B}$ & $0,63 \mathrm{~A}$ & 0,049 & 0,029 & 0,314 \\
\hline & $0,02 \mathrm{aAB}$ & $0,01 \mathrm{bB}$ & $08 \mathrm{aAB}$ & 0,0 & 0,0 & 0,06 & - & & & \\
\hline \multirow[t]{2}{*}{$\mathrm{C} 22: 1 \omega 9$} & $0,00 \mathrm{aB}$ & $0,08 \mathrm{aAB}$ & $0,05 \mathrm{aAB}$ & $0,11 \mathrm{aA}$ & $0,01 \mathrm{bB}$ & - & 0,05 & 0,001 & 0,501 & 0,008 \\
\hline & $0,01 \mathrm{~B}$ & $0,04 \mathrm{~B}$ & $0,07 \mathrm{AB}$ & 0,1 & $0,05 \mathrm{AB}$ & - & - & & & \\
\hline $\mathrm{C} 20: 3 \omega$ & & 0,02 & 0,01 & 0,00 & 0,00 & 0,02 & 0,01 & 0,129 & 0,120 & 0,334 \\
\hline C20:4 46 & $6,58 \mathrm{~B}$ & $7,91 \mathrm{~B}$ & $11,54 \mathrm{~A}$ & $11,48 \mathrm{~A}$ & $9,19 \mathrm{AB}$ & 9,01 & 9,66 & 0,001 & 0,378 & 0,368 \\
\hline $\mathrm{C} 22: 6 \omega 3$ & $0,29 \mathrm{C}$ & $0,66 \mathrm{BC}$ & $1,41 \mathrm{~A}$ & $1,25 \mathrm{~A}$ & $0,82 \mathrm{~B}$ & 0,83 & 0,95 & 0,001 & 0,210 & 0,291 \\
\hline
\end{tabular}

${ }^{1}$ Teste de Tukey $(\alpha=0,05)$; médias seguidas por letras minúsculas $(\mathrm{ab})$ na coluna indicam diferença entre sexo; médias seguidas por letras maiúsculas $(\mathrm{AB})$ na linha indicam diferença entre genótipos e entre sexos; NHS - New Hampshire; GNJ - Gigante Negra de Jersey; IG - Índio Gigante; IG x NHS - cruzamento entre aves da raça Índio Gigante e New Hampshire; IG x GNJ - cruzamento entre aves da raça Índio Gigante e Gigante Negra de Jersey.

Houve influência isolada do sexo sobre a composição dos ácidos graxos do peito, com maiores médias de $\mathrm{C} 22: 0$ e $\mathrm{C} 20: 3 \omega 6$ para as fêmeas e de C15:0 e C17:0 para os machos. Eleroğlu et al. (2013), quando avaliaram o efeito do sexo sobre o conteúdo de ácidos graxos da carne de peito, observaram maiores teores de C16:0 e C20:0 para as fêmeas e reportaram que as diferenças em relação à composição lipídica para aves criadas em sistema alternativo podem ser devido ao comportamento alimentar entre sexos, levando em consideração principalmente o consumo de forragem fresca.

Em geral, trabalhos na literatura indicam que os teores de ácido graxo da carne de peito variam entre diferentes linhagens (Castellini et al., 2006; Tang et al., 2009; Sirri et al., 2010; 2011; Dal
Bosco et al., 2012; Kuçukyilmaz et al., 2012). Para os ácidos graxos C12:0, as aves do cruzamento IG $\mathrm{x}$ NHS apresentaram a maior média; para $\mathrm{C} 16: 0$, as aves oriundas de cruzamentos IG $x$ NHS $\mathrm{e}$ IG $\mathrm{x}$ GNJ demonstraram os maiores valores, sendo, no entanto, semelhantes aos genótipos NHS e IG (Tab. 2), revelando, assim, que o uso de cruzamentos entre raças de diferentes origens pode promover modificação no teor de ácidos graxos saturados, bem como as aves IG x NHS, que apresentaram maiores concentrações de C18:0 (ácido esteárico).

Os principais ácidos graxos monoinsaturados encontrados na carne de peito das aves foram o C16:1 (ácido palmitoleico) e o C18:109c (ácido oleico), com maiores médias para aves NHS e GNJ 
(Tab. 2). As diferenças entre genótipos nas concentrações desses ácidos graxos na carne podem ser em razão da maior atividade da enzima $\Delta$ 9-dessaturase (Laborde et al., 2001).

O genótipo GNJ apresentou a maior média de

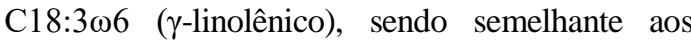
genótipos NHS e IG x GNJ, enquanto para os ácidos graxos C20:4 66 (ácido araquidônico) e C22:6 63 (ácido docosa-hexanoico - DHA), os genótipos IG e IG x NHS apresentaram os maiores teores no peito (Tab. 2). Como a raça IG é empregada mais para a ornamentação, esta, ao longo de sua formação, não foi utilizada para a produção de carne, apresentando, portanto, um desenvolvimento mais tardio quando comparada às outras raças, tais como a NHS e a GNJ. Sirri et al. (2010) também encontraram diferenças para os teores de DHA e ácido araquidônico entre aves de diferentes linhagens em função da taxa de crescimento e observaram que há uma tendência de as aves de crescimento lento apresentarem na musculatura de duas a três vezes mais conteúdo de $\omega 3$, tais como o EPA e o DHA. Segundo Dal Bosco et al. (2012), a alta eficiência de deposição destes ácidos graxos de cadeia longa em aves de crescimento tardio pode ser explicada por questões genéticas e pelo comportamento alimentar, sendo a maior intensidade de pastejo o fator responsável pelo aumento do consumo de forragens que são ricas em ácido linolênico e promoveriam, consequentemente, o aumento da conversão em EPA e DHA.

No corte do peito, para SAT, o genótipo IG x NHS apresentou a maior média e foi semelhante às suas raças formadoras (NHS e IG) e ao genótipo IG x GNJ (Tab. 3). Com relação ao MON, os genótipos NHS e GNJ apresentaram os maiores conteúdos e não houve efeito sobre o total de ácidos graxos $\omega 6$. Resultados na literatura mostram correspondência entre o grau de desenvolvimento dos genótipos para a produção de carne, a precocidade e o ganho de peso com o conteúdo de MON na carne de peito (Sirri et al., 2010; Dal Bosco et al., 2012).

Foram observados maiores teores de POL e $\omega 3$, além de melhor relação $\omega 6 / \omega 3$ na carne do peito para os genótipos IG x NHS e IG (Tab. 3). Esses resultados demonstram um efeito positivo do cruzamento sobre a composição lipídica da carne das aves, uma vez que o consumo de dietas ricas em ácidos graxos $\omega 3$ promove uma diminuição no risco de ocorrência de doenças cardíacas (Jump et al., 2012).

Tabela 3. Somatório de ácidos graxos e índices enzimáticos da carne de peito

\begin{tabular}{|c|c|c|c|c|c|c|c|c|c|c|}
\hline Variável & \multicolumn{5}{|c|}{ Genótipo (G) } & \multicolumn{2}{|c|}{ Sexo $(\mathrm{S})$} & \multicolumn{3}{|c|}{$\overline{\mathrm{P}^{1}}$} \\
\hline Soma & NHS & GNJ & IG & IG x NHS & IG x GNJ & Macho & Fêmea & $\mathrm{G}$ & $\mathrm{S}$ & GxS \\
\hline âT & $35,95 \mathrm{AB}$ & $35,47 \mathrm{~B}$ & $36,69 \mathrm{AB}$ & $38,34 \mathrm{~A}$ & $37,17 \mathrm{AB}$ & 37,19 & 36,26 & 0,032 & 0,117 & 0,409 \\
\hline${ }^{\mathrm{b}} \mathrm{MON}$ & $36,92 \mathrm{~A}$ & $34,51 \mathrm{AB}$ & $31,23 \mathrm{BC}$ & $29,27 \mathrm{C}$ & $32,37 \mathrm{BC}$ & 32,88 & 32,84 & 0,001 & 0,969 & 0,371 \\
\hline${ }^{\mathrm{C}} \mathrm{POL}$ & 27,13B & $30,02 \mathrm{AB}$ & $32,11 \mathrm{~A}$ & $32,40 \mathrm{~A}$ & $30,46 \mathrm{AB}$ & 29,94 & 30,9 & 0,013 & 0,338 & 0,694 \\
\hline${ }^{\mathrm{d}} \Sigma \omega 3$ & $0,76 \mathrm{~B}$ & $1,47 \mathrm{AB}$ & $2,11 \mathrm{~A}$ & $2,11 \mathrm{~A}$ & $1,52 \mathrm{AB}$ & 1,62 & 1,56 & 0,001 & 0,783 & 0,221 \\
\hline${ }^{\mathrm{e}} \Sigma \omega 6$ & 26,14 & 28,28 & 29,69 & 29 , & & 28,01 & 29,07 & 0,074 & 0,245 & 0,419 \\
\hline RELAÇÃO & & & & & & & & & & \\
\hline${ }^{\mathrm{f}} \Sigma \omega 6 / \Sigma \omega 3$ & $53,59 \mathrm{~A}$ & $23,07 \mathrm{AB}$ & $16,46 \mathrm{~B}$ & $16,27 \mathrm{~B}$ & $21,90 \mathrm{AB}$ & 22,87 & 29,65 & 0,032 & 0,409 & 0,372 \\
\hline $\begin{array}{l}{ }^{g} \mathrm{POL} / \mathrm{SAT} \\
\text { Îndice }\end{array}$ & 0,76 & 0,85 & 0,88 & 0,85 & 0,83 & 0,81 & 0,85 & 0,225 & 0,203 & 0,775 \\
\hline${ }^{\mathrm{h}} \Delta 9$-dessaturase ${ }^{\mathrm{C} 16}$ & $75,59 \mathrm{~A}$ & $73,76 \mathrm{AB}$ & $69,61 \mathrm{BC}$ & $68,02 \mathrm{C}$ & $71,37 \mathrm{ABC}$ & 71,24 & 72,09 & 0,001 & 0,416 & 0,642 \\
\hline${ }^{\mathrm{i}} \Delta 9$-dessat & $9,84 \mathrm{~A}$ & $8,55 \mathrm{AB}$ & $5,58 \mathrm{C}$ & $4,54 \mathrm{C}$ & $6,67 \mathrm{BC}$ & 7,04 & 7,03 & 0,001 & 0,982 & 0,325 \\
\hline${ }^{\mathrm{j}}$ Elong & 62,33 & 63,01 & 62,6 & & & 62,09 & 62,21 & 0,055 & 0,779 & 0,322 \\
\hline${ }^{\mathrm{k}}$ Tioesterase $\mathrm{C}^{\mathrm{C} 16-14}$ & 97,22 & 96,68 & 96,96 & 95,27 & 96,68 & 96,18 & 96,95 & 0,154 & 0,139 & 0,435 \\
\hline${ }^{1}$ Aterogenicidade & 0,42 & 0,39 & 0,37 & 0,40 & 0,40 & 0,40 & 0,39 & 0,245 & 0,275 & 0,372 \\
\hline${ }^{\mathrm{m}}$ Trombogenicidade & 1,03 & 0,96 & 0,97 & 1,03 & 1,03 & 1,02 & 0,99 & 0,234 & 0,240 & 0,880 \\
\hline
\end{tabular}

${ }^{1}$ Teste de Tukey $(\alpha=0,05)$; médias seguidas por letras maiúsculas (AB) na linha indicam diferença entre genótipos; NHS - New Hampshire; GNJ - Gigante Negra de Jersey; IG - Índio Gigante; IG x NHS - cruzamento entre aves da raça Índio Gigante e New Hampshire; IG x GNJ - cruzamento entre aves da raça Índio Gigante e Gigante Negra de Jersey; ${ }^{a}$ total de ácidos graxos saturados; ${ }^{b}$ total de ácidos graxos monoinsaturados; ${ }^{\circ}$ total de ácidos graxos poliinsaturados; ${ }^{\mathrm{d}}$ total de ácidos graxos ômega 3; ${ }^{\mathrm{e}}$ soma de ácidos graxos ômega 6; ${ }^{\mathrm{f}}$ relação ômega 6/ômega 3 ; ${ }^{\mathrm{g}}$ relação

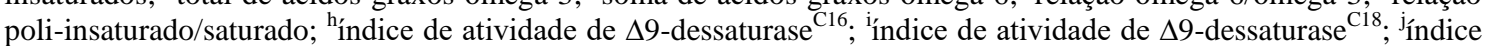
de atividade de elongase ${ }^{\mathrm{C} 16-\mathrm{C} 18}$; ${ }^{\mathrm{k}}$ índice de atividade de tioesterase ${ }^{\mathrm{C} 16-\mathrm{C} 14}$; líndice de aterogenicidade; ${ }^{\mathrm{m}}$ índice de trombogenicidade. 
Ao se comparar a composição lipídica de diferentes linhagens de frangos de corte em função do potencial de crescimento, em geral, observam-se maiores concentrações de POL, $\omega 3$ e $\omega 6$ do peito para as linhagens de crescimento lento (Castellini et al., 2006; Tang et al., 2009; Sirri et al., 2010). Segundo Castellini et al. (2006), a diferença nos valores de SAT, POL, MON e $\omega 3$ entre linhagens de frangos se deve ao comportamento em relação ao tempo de pastejo, consequentemente, à quantidade de gramíneas ingeridas, que são fontes de ácidos graxos 13 . Assim, verifica-se que linhagens mais precoces e com taxa de crescimento superior para produção de carne apresentaram um maior consumo de ração para expressar o seu potencial de produção e atender a necessidade proteica e, consequentemente, uma menor ingestão de forragens (Dal Bosco et al., 2012), o que se confirma ao observado neste estudo, em que as aves da raça Índio Gigante, apesar de maior porte, apresentam menor precocidade.

Segundo a World Health Organization (Diet..., 2003), a ingestão de dieta com relação de $\omega 6 / \omega 3$ em torno de 4:1 auxilia na prevenção do desenvolvimento de doenças inflamatórias, alérgicas e cardiovasculares. Os resultados para a carne dos animais deste estudo variaram em torno de 16:1 até 53:1, com maiores médias para a linhagem NHS e menor para IG. De forma semelhante, Sirri et al. (2010) verificaram diferença na relação $\omega 6 / \omega 3$ para frangos de diferentes grupos genéticos, com média de 4,34:1 para aves de crescimento lento e de 6,83:1 para as de crescimento rápido, indicando que o fator precocidade modifica o perfil lipídico e promove essa alteração, como verificado neste estudo, justificando as diferenças encontradas.

Os genótipos NHS e GNJ apresentaram valores superiores para $\Delta 9$-dessaturase ${ }^{\mathrm{Cl6}}$ e $\Delta 9$ dessaturase $^{\mathrm{Cl1}}$; IG e IG $\mathrm{x}$ NHS valores intermediários; e IG x GNJ inferiores (Tab. 3), o que pode ser justificado pelas maiores

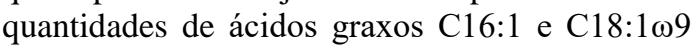
para essas aves. Dal Bosco et al. (2012) também encontraram diferenças entre linhagens sobre os índices de atividade dessas enzimas, tendo as aves de crescimento lento apresentado valores inferiores. Segundo Kouba et al. (2003), a atividade das enzimas $\Delta 9$-dessaturases diminui com o aumento da ingestão de ácido linolênico, o que pode estar associado a uma maior intensidade de pastejo e ao consumo de forragens frescas (Castellini et al., 2006). Dessa forma, as aves com menor precocidade, como IG, manifestariam uma maior tendência a apresentarem redução nos índices de atividade das enzimas $\Delta 9$-dessaturases.

Os machos das aves NHS apresentaram maiores

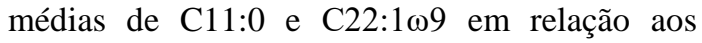
demais grupos genéticos para coxa (Tab. 4). Para os teores de C22:1 $\omega 9$ da coxa, houve diferenças entre sexos apenas para aves do genótipo GNJ, em que os machos apresentaram a maior média, enquanto para as aves GNJ e IG x NHS, os machos apresentaram os maiores teores.

Foram observadas maiores médias de C16:0 e C22:0 para os genótipos NHS e GNJ, e de C18:0 para os genótipos IG e IG x NHS (Tab. 4). Sirri et al. (2010) observaram maiores teores de C14:0 e C16:0 na carne de coxa de linhagens de crescimento rápido, porém menores teores de C18:0. Segundo Castellini et al. (2008), as diferenças nos teores de ácidos graxos saturados na coxa podem estar relacionadas ao comportamento das aves, em que linhagens de crescimento lento apresentam maior locomoção e estariam utilizando esses ácidos graxos como fonte de energia.

Com relação aos conteúdos de ácidos graxos monoinsaturados da coxa, os genótipos NHS, GNJ e IG x GNJ apresentaram maiores valores

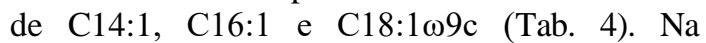
literatura, são relatados maiores teores de C16:1 e C18:169c na coxa, para aves de crescimento rápido (Tang et al., 2009; Sirri et al., 2010; 2011), o que é justificado pelos autores devido à maior atividade das enzimas $\Delta 9$-dessaturases.

Houve efeito do genótipo para o ácido graxo C18:3 $\omega 6$ (ácido $\gamma$-linolênico) da coxa, em que as aves GNJ apresentaram a maior média, enquanto para C20:2 e C20:3 106 deste corte, os genótipos IG e IG x NHS apresentaram os maiores valores

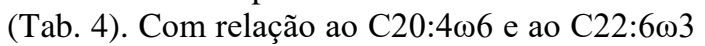
(DHA) na coxa, os genótipos IG e NHS apresentaram os maiores e menores teores, respectivamente (Tab. 4). Sirri et al. (2010) observaram maiores teores de DHA da coxa para a linhagem de crescimento lento, quando comparada às de crescimento médio e rápido. Os autores atribuíram esses resultados à atividade da enzima $\Delta 6$-dessaturase, que está diretamente 
relacionada à conversão de $\mathrm{C} 18: 3 \omega 3$ (ácido linolênico) em C20:5 $\omega 3$ (EPA) e C22:6 13 (DHA). Isso demonstra um resultado desejável para o consumidor, pois o DHA é um dos mais importantes ácidos graxos $\omega 3$, uma vez que exerce funções essenciais no organismo, sendo fundamental para a formação do tecido nervoso e visual (Crawford et al., 1994), da mesma forma que o ácido araquidônico é considerado essencial ao organismo animal, ocorrendo a sua síntese a partir do C18:2 66 (ácido linoleico) (Perini et al., 2010).

Tabela 4. Perfil de ácidos graxos da coxa de frangos de corte criados em sistema alternativo

\begin{tabular}{|c|c|c|c|c|c|c|c|c|c|c|}
\hline \multirow{2}{*}{$\begin{array}{r}\text { Variável } \\
\text { Ácido graxo }\end{array}$} & \multicolumn{5}{|c|}{ Genótipo (G) } & \multicolumn{2}{|c|}{ Sexo (S) } & \multicolumn{3}{|c|}{$\mathrm{P}^{1}$} \\
\hline & NHS & GNJ & IG & IG x NHS & IG x GNJ & Macho & Fêmea & $\mathrm{G}$ & $\mathrm{S}$ & GxS \\
\hline \multirow[t]{2}{*}{ C10:0 } & 0,05 & 0,03 & 0,09 & 0,03 & 0,02 & 0,06 & 0,02 & 0,471 & 0,136 & 0,789 \\
\hline & $0,07 \mathrm{aA}$ & $0,00 \mathrm{aB}$ & $0,00 \mathrm{aB}$ & $0,00 \mathrm{aB}$ & $0,00 \mathrm{aB}$ & 0,01 & - & & & \\
\hline \multirow[t]{2}{*}{ C11:0 } & $0,00 \mathrm{bA}$ & $0,00 \mathrm{aA}$ & $0,03 \mathrm{aA}$ & $0,00 \mathrm{aA}$ & $0,00 \mathrm{aA}$ & - & 0,01 & 0,034 & 0,323 & 0,012 \\
\hline & 0,04 & 0,00 & 0,01 & 0,00 & 0,00 & - & - & & & \\
\hline C12:0 & 0,04 & 0,15 & 0,25 & 0,17 & 0,05 & 0,14 & 0,13 & 0,034 & 0,898 & 0,137 \\
\hline C14:0 & 0,70 & 0,88 & 0,60 & 0,79 & 0,62 & 0,70 & 0,70 & 0,064 & 0,342 & 0,142 \\
\hline C14:1 & $0,10 \mathrm{~A}$ & $0,09 \mathrm{AB}$ & $0,04 \mathrm{C}$ & $0,05 \mathrm{BC}$ & $0,09 \mathrm{~A}$ & 0,08 & 0,07 & 0,001 & 0,483 & 0,306 \\
\hline C15:0 & 0,18 & 0,19 & 0,19 & 0,16 & 0,16 & $0,21 \mathrm{~A}$ & $0,14 \mathrm{~B}$ & 0,894 & 0,024 & 0,235 \\
\hline C16:0 & $23,23 \mathrm{~A}$ & $22,72 \mathrm{~A}$ & $19,97 \mathrm{C}$ & $21,36 \mathrm{~B}$ & $22,15 \mathrm{AB}$ & 21,84 & 21,93 & 0,001 & 0,756 & 0,583 \\
\hline C16:1 & $3,51 \mathrm{~A}$ & $3,04 \mathrm{~A}$ & $1,71 \mathrm{~B}$ & $1,88 \mathrm{~B}$ & $3,41 \mathrm{~A}$ & 2,66 & 2,76 & 0,001 & 0,598 & 0,662 \\
\hline C17:0 & 0,38 & 0,40 & 0,42 & 0,31 & 0,33 & 0,44 & 0,30 & 0,841 & 0,059 & 0,205 \\
\hline C17:1 & 0,30 & 0,33 & 0,42 & 0,22 & 0,25 & 0,32 & 0,28 & 0,154 & 0,438 & 0,165 \\
\hline C18:0 & $9,45 \mathrm{C}$ & $10,48 \mathrm{BC}$ & $12,95 \mathrm{~A}$ & $11,77 \mathrm{AB}$ & $9,53 \mathrm{C}$ & 11,18 & 10,49 & 0,001 & 0,079 & 0,709 \\
\hline $\mathrm{C} 18: 1 \omega 9 \mathrm{t}$ & 0,43 & 0,42 & 0,75 & 0,44 & 0,53 & 0,55 & 0,48 & 0,456 & 0,604 & 0,098 \\
\hline $\mathrm{C} 18: 1 \omega 9 \mathrm{c}$ & $34,95 \mathrm{~A}$ & $32,42 \mathrm{AB}$ & $28,77 \mathrm{C}$ & $30,19 \mathrm{BC}$ & $33,78 \mathrm{~A}$ & $31,09 \mathrm{~B}$ & $32,96 \mathrm{~A}$ & 0.001 & 0,006 & 0,513 \\
\hline $\mathrm{C} 18: 2 \omega 6 \mathrm{c}$ & 21,12 & 21,33 & 21,79 & 23,24 & 22,97 & 22,43 & 22,42 & 0,074 & 0,242 & 0,496 \\
\hline C20:0 & 0,09 & 0,09 & 0,10 & 0,08 & 0,09 & 0,09 & 0,09 & 0,471 & 0,159 & 0,405 \\
\hline $\mathrm{C} 18: 3 \omega 6$ & $0,11 \mathrm{AB}$ & $0,14 \mathrm{~A}$ & $0,08 \mathrm{C}$ & $0,07 \mathrm{C}$ & $0,10 \mathrm{BC}$ & 0,10 & 0,10 & 0,001 & 0,587 & 0,505 \\
\hline$C: 20: 1$ & 0,23 & 0,18 & 0,23 & 0,25 & 0,23 & 0,23 & 0,22 & 0,199 & 0,738 & 0,415 \\
\hline $\mathrm{C} 18: 3 \omega 3$ & 0,58 & 0,86 & 0,68 & 0,78 & 0,67 & 0,65 & 0,78 & 0,392 & 0,174 & 0,361 \\
\hline C20:2 & $0,19 \mathrm{~B}$ & $0,23 \mathrm{AB}$ & $0,28 \mathrm{~A}$ & $0,29 \mathrm{~A}$ & $0,22 \mathrm{AB}$ & $0,26 \mathrm{~A}$ & $0,22 \mathrm{~B}$ & 0,001 & 0,009 & 0,249 \\
\hline C22:0 & $0,07 \mathrm{AB}$ & $0,08 \mathrm{~A}$ & $0,05 \mathrm{AB}$ & $0,04 \mathrm{AB}$ & $0,04 \mathrm{~B}$ & $0,43 \mathrm{~B}$ & $0,68 \mathrm{~A}$ & 0,032 & 0,012 & 0,871 \\
\hline \multirow[t]{2}{*}{$\mathrm{C} 20: 3 \omega 6$} & $0,28 \mathrm{AB}$ & $0,37 \mathrm{AB}$ & $0,38 \mathrm{~A}$ & $0,33 \mathrm{AB}$ & $0,24 \mathrm{~B}$ & 0,32 & 0,32 & 0,024 & 0,915 & 0,900 \\
\hline & $0,06 \mathrm{aA}$ & $0,02 \mathrm{bA}$ & $0,05 \mathrm{aA}$ & $0,07 \mathrm{aA}$ & $0,03 \mathrm{aA}$ & 0,05 & - & & & \\
\hline \multirow[t]{2}{*}{$\mathrm{C} 22: 1 \omega 9$} & $0,00 \mathrm{aB}$ & $0,09 \mathrm{aA}$ & $0,02 \mathrm{aAB}$ & $0,09 \mathrm{aA}$ & $0,01 \mathrm{aAB}$ & - & 0,04 & 0,057 & 0,786 & 0,037 \\
\hline & 0,03 & 0,05 & 0,04 & 0,08 & 0,02 & - & - & & & \\
\hline $\mathrm{C} 20: 3 \omega 3$ & 0,00 & 0,02 & 0,04 & 0,00 & 0,03 & 0,16 & 0,18 & 0,120 & 0,859 & 0,540 \\
\hline $\mathrm{C} 20: 4 \omega 6$ & $3,78 \mathrm{C}$ & $5,12 \mathrm{BC}$ & $9,26 \mathrm{~A}$ & $6,82 \mathrm{~B}$ & $4,15 \mathrm{C}$ & 6,01 & 5,64 & 0,001 & 0,455 & 0,685 \\
\hline $\mathrm{C} 22: 6 \omega 3$ & $0,16 \mathrm{~B}$ & $0,34 \mathrm{~B}$ & $0,90 \mathrm{~A}$ & $0,66 \mathrm{~A}$ & $0,32 \mathrm{~B}$ & 0,47 & 0,48 & 0,001 & 0,876 & 0,624 \\
\hline
\end{tabular}

1Teste de Tukey $(\alpha=0,05)$; médias seguidas por letras minúsculas (ab) na coluna indicam diferença entre sexo; médias seguidas por letras maiúsculas $(\mathrm{AB})$ na linha indicam diferença entre genótipos e entre sexos; NHS - New Hampshire; GNJ - Gigante Negra de Jersey; IG - Índio Gigante; IG x NHS - cruzamento entre aves da raça Índio Gigante e New Hampshire; IG x GNJ - cruzamento entre aves da raça Índio Gigante e Gigante Negra de Jersey.

As aves de genótipos NHS e IG x GNJ apresentaram maiores valores de MON da coxa (Tab. 5). Trabalhos na literatura indicam uma tendência de que linhagens de crescimento rápido apresentem maiores teores de MON na coxa (Tang et al., 2009; Sirri et al., 2010; 2011), o que se deve principalmente aos teores elevados

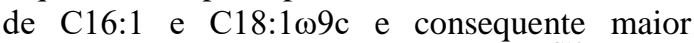
atividade da enzima $\Delta 9$-dessaturase ${ }^{\mathrm{C} 18}$, como verificado neste estudo para essas linhagens.

A taxa de precocidade pode influenciar a composição lipídica (Tang et al., 2009; Sirri et al., 2010, 2011), o que pode ser observado nos produtos oriundos do cruzamento entre IG e
NHS que produziu descendentes com maiores teores de POL, $\omega 3$ e $\omega 6$.

As aves da raça NHS apresentaram na carne da coxa maior valor na relação de $\omega 6 / \omega 3$ e menor para POL/SAT, enquanto o grupo IG apresentou comportamento inverso. Esse comportamento está relacionado a sua maior precocidade e taxa de crescimento para produção de carne (Dal Bosco et al., 2012; Albino et al., 2014) em comparação aos outros genótipos, como as aves da raça $\mathrm{IG}$, que têm características de crescimento lento, apesar do seu maior porte (Castellini et al., 2006; ABCIG, 2016). 
Tabela 5. Somatório de ácidos graxos e índices enzimáticos da carne de coxa

\begin{tabular}{|c|c|c|c|c|c|c|c|c|c|c|}
\hline Variável & & & Genótipo & & & Sex & (S) & & $\mathrm{P}^{1}$ & \\
\hline Soma & NHS & GNJ & IG & IG x NHS & IG x GNJ & Macho & Fêmea & G & $\mathrm{S}$ & GxS \\
\hline âAFA & 34,22 & 35,03 & 34,62 & 34,71 & 33,00 & 34,77 & 33,86 & 0,147 & 0,090 & 0,345 \\
\hline${ }^{\mathrm{b}} \mathrm{MON}$ & $39,54 \mathrm{~A}$ & $36,53 \mathrm{AB}$ & $31,96 \mathrm{C}$ & $33,11 \mathrm{BC}$ & $38,31 \mathrm{~A}$ & $34,97 \mathrm{~B}$ & $36,81 \mathrm{~A}$ & 0,001 & 0,024 & 0,689 \\
\hline${ }^{\mathrm{C}} \mathrm{POL}$ & $26,23 \mathrm{~B}$ & $28,40 \mathrm{~B}$ & $33,42 \mathrm{~A}$ & $32,18 \mathrm{~A}$ & $28,69 \mathrm{~B}$ & 30,26 & 29,31 & 0,001 & 0,167 & 0,559 \\
\hline${ }^{\mathrm{d}} \Sigma \omega 3$ & $0,74 \mathrm{C}$ & $1,22 \mathrm{AB}$ & $1,63 \mathrm{~A}$ & $1,44 \mathrm{AB}$ & $1,02 \mathrm{BC}$ & 1,38 & 1,28 & 0,001 & 0,180 & 0,199 \\
\hline${ }^{\mathrm{e}} \Sigma \omega 6$ & $25,29 \mathrm{~B}$ & $26,96 \mathrm{~B}$ & $31,51 \mathrm{~A}$ & $30,46 \mathrm{~A}$ & $27,45 \mathrm{~B}$ & 28,86 & 27,81 & 0,001 & 0,102 & 0,638 \\
\hline Relaç & & & & & & & & & & \\
\hline${ }^{\mathrm{f}} \Sigma \omega 6 / \Sigma \omega 3$ & $35,10 \mathrm{~A}$ & $22,24 \mathrm{BC}$ & $20,97 \mathrm{C}$ & $22,41 \mathrm{BC}$ & $28,12 \mathrm{AB}$ & $28,21 \mathrm{~A}$ & $24,13 \mathrm{~B}$ & 0,001 & 0,013 & 0,158 \\
\hline $\begin{array}{l}{ }^{g} \text { POL/SAT } \\
\text { Índice }\end{array}$ & $0,77 \mathrm{~B}$ & $0,82 \mathrm{~B}$ & $0,97 \mathrm{~A}$ & $0,93 \mathrm{~A}$ & $0,87 \mathrm{AB}$ & 0,88 & 0,87 & 0,001 & 0,690 & 0,381 \\
\hline${ }^{\mathrm{h}} \Delta 9$-dessaturase ${ }^{\mathrm{C} 16}$ & $78,66 \mathrm{~A}$ & $75,46 \mathrm{AB}$ & $68,91 \mathrm{C}$ & $71,84 \mathrm{BC}$ & 77,9 & $73,44 \mathrm{~B}$ & $75,69 \mathrm{~A}$ & 0,001 & 0,031 & 0,673 \\
\hline${ }^{\mathrm{i}} \Delta 9$-des & $13,10 \mathrm{~A}$ & $11,81 \mathrm{~A}$ & $7,83 \mathrm{~B}$ & $8,05 \mathrm{~B}$ & 13,3 & 10,67 & 10,96 & 0,001 & 0,648 & 0,613 \\
\hline 'Elon: & $62,42 \mathrm{C}$ & $62,46 \mathrm{C}$ & $65,83 \mathrm{~A}$ & $64,35 \mathrm{AB}$ & 62,8 & 63,37 & 63 & 0,001 & 0,269 & 0,866 \\
\hline${ }^{\mathrm{k}}$ Tioeste & & & 97,14 & & & 96,7 & 0 & 0,105 & 0,290 & 0,111 \\
\hline 'Aterog & $0,43 \mathrm{~A}$ & $0,42 \mathrm{~A}$ & $0,33 \mathrm{C}$ & $0,37 \mathrm{~B}$ & $0,40 \mathrm{AB}$ & 0,38 & 0,39 & 0,001 & 0,298 & 0,958 \\
\hline${ }^{\mathrm{m}}$ Trombogenicidade & 0,97 & 0,97 & 0,92 & 0,94 & 0,90 & $0,96 \mathrm{~A}$ & $0,92 \mathrm{~B}$ & 0,186 & 0,042 & 0,342 \\
\hline
\end{tabular}

${ }^{1}$ Teste de Tukey $(\alpha=0,05)$; médias seguidas por letras maiúsculas $(\mathrm{AB})$ na linha indicam diferença entre genótipos e entre sexos; NHS - New Hampshire; GNJ - Gigante Negra de Jersey; IG - Índio Gigante; IG x NHS - cruzamento entre aves da raça Índio Gigante e New Hampshire; IG x GNJ - cruzamento entre aves da raça Índio Gigante e Gigante Negra de Jersey; ${ }^{a}$ total de ácidos graxos saturados; ' total de ácidos graxos monoinsaturados; ' total de ácidos graxos poli-insaturados; ' total de ácidos graxos ômega 3; 'total de ácidos graxos ômega 6; ' relação ômega 6/ômega 3; ${ }^{\mathrm{g}}$ relação poli-insaturado/saturado; 'índice de atividade de $\Delta 9$ dessaturase ${ }^{\mathrm{C} 16}$; índice de atividade de $\Delta 9$-dessaturase ${ }^{\mathrm{C} 18}$; 'índice de atividade de elongase ${ }^{\mathrm{C} 16-\mathrm{C} 18}$; ${ }^{\mathrm{K}}$ índice de atividade de tioesterase ${ }^{\mathrm{C} 16-}$ ${ }^{\mathrm{C} 14}$; ' 'índice de aterogenicidade; 'índice de trombogenicidade.

Com relação ao índice de atividade das enzimas $\Delta 9$-dessaturase ${ }^{\mathrm{C} 16}$ e $\Delta 9$-dessaturase ${ }^{\mathrm{C} 18}$ na coxa, os genótipos NHS, GNJ e IG x GNJ apresentaram os maiores valores (Tab. 5), o que está relacionado ao maior conteúdo de MON. Segundo Kouba et al. (2003), o índice de atividade das enzimas $\Delta 9$-dessaturases é inversamente proporcional ao conteúdo de $\omega 3$ na carne, e isso faz com que as aves de crescimento mais acelerado, tais como NHS e GNJ, apresentem menor deposição desses ácidos graxos e, consequentemente, maior atividade dessas enzimas.

As aves da raça IG e do cruzamento IG x NHS apresentaram o maior índice de atividade da enzima elongase $^{\mathrm{C} 16-\mathrm{C} 18}$ na coxa (Tab. 5). Dal Bosco et al. (2012) observaram, em razão do potencial de crescimento, maiores valores desse índice para aves com menores taxas de crescimento e com aptidão para a produção de ovos, o que, segundo Alessandri et al. (2012), deve-se principalmente aos fatores hormonais.

Para o índice de aterogenicidade da coxa, os genótipos NHS e GNJ apresentaram as maiores médias, enquanto o IG apresentou o menor valor. Esse comportamento pode estar relacionado ao menor conteúdo de POL na carne dessas aves, uma vez que esses parâmetros são inversamente proporcionais. Por outro lado, aves com menores taxas de crescimento apresentaram maiores conteúdos de POL na carne, contribuindo para a diminuição nos valores de índice de aterogenicidade, como verificado na raça IG. Contudo, para o índice de trombogenicidade, não houve diferença entre os genótipos (Tab. 5). Sirri et al. (2011) encontraram aumento nos índices de aterogenicidade e de trombogenicidade em função da taxa de precocidade, o que confirma o observado decido às características de crescimento das aves deste estudo.

Com relação ao sexo, os machos apresentaram maiores teores dos ácidos graxos C15:0, C20:2, da relação $\omega 6 / \omega 3$ e de índice de trombogenicidade da coxa, e, em contrapartida, foram observados maiores teores de $\mathrm{C} 18: 1 \omega 9 \mathrm{c}$, C22:0, MON e maior valor do índice de $\Delta 9$ dessaturase ${ }^{\mathrm{C} 16}$ para as fêmeas (Tab. 4 e 5).

Estes resultados foram semelhantes aos observados por Poureslami et al. (2010) e Quaresma et al. (2016), que observaram maiores

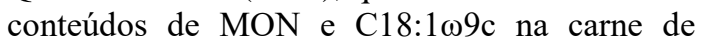
fêmeas de frangos de corte e faisão, respectivamente, sendo essas diferenças devido aos fatores hormonais, que podem afetar diretamente as atividades enzimáticas, provocando, assim, alterações no metabolismo e deposição de ácidos graxos.

Diferenças encontradas na relação $\omega 6 / \omega 3$ podem ser devido à atividade de $\beta$-oxidação dos ácidos 
graxos precursores da formação dos ácidos graxos de cadeia longa, uma vez que, em frangos de corte machos, há uma maior atividade de $\beta$ -

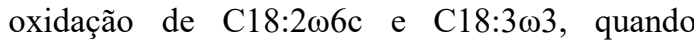
comparados às fêmeas (Poureslami et al., 2010). Isso pode levar a uma maior disponibilidade de C18:3 $\omega 3$ e de seus precursores da série $\omega 3 \mathrm{em}$ fêmeas, provocando, assim, uma diminuição na relação $\omega 6 / \omega 3$.

\section{CONCLUSÃO}

O cruzamento entre as raças IG e NHS proporcionou descendentes com melhor perfil lipídico na carne devido a maiores conteúdos de ácido araquidônico, DHA e $\omega 3$ em ambos os cortes. As fêmeas apresentaram melhor perfil lipídico da coxa, em razão da menor relação $\omega 6 / \omega 3$.

\section{REFERÊNCIAS}

ALBINO, L.F.T.; TAVERNARI, F.C.; VIEIRA, R.A.; NERY, L.R. Aves mais indicadas. In: (Ed.). Criação de frango e galinha caipira sistema alternativo de criação de aves. [s.1.]: Aprenda Fácil, 2014. p.21-29.

ALESSANDRI, J.M.; EXTIER, A.; ALGUBORY, K.H. Influence of gender on DHA synthesis: the response of rat liver to low dietary $\alpha$-linolenic acid evidences higher $\omega 3 \quad \Delta 4$ desaturation index in females. Eur. J. Nutr., v.51, p.199-209, 2012.

BRASIL. Ministério da Agricultura Pecuária e Abastecimento. Ofício Circular DOI/DIPOA n ${ }^{\circ}$ 7, de 19 de maio de 1999. Normatização e comercialização do frango Caipira ou frango Colonial, também denominado "Frango Tipo ou Estilo Caipira" ou "Tipo ou Estilo Colonial". Diário Oficial da União. Brasília, 1999.

CASTELLINI, C.; BERRI, C.; LE BIHANDUVAL, E.; MARTINO, G. Qualitative attributes and consumer perception of organic and free-range poultry meat. World's Poult. Sci. J., v.64, p.500-512, 2008.

CASTELLINI, C.; DAL BOSCO, A.; MUGNAI, C.; PEDRAZZOLI, M. Comparison of two chicken genotypes organically reared: oxidative stability and other qualitative traits of the meat. Ital. J. Anim. Sci., v.5, p.355-363, 2006.
ASSOCIAÇÃO Brasileira dos Criadores de Índio Gigante, 2016. Disponível em: <http://abcig.com.br/>. Acessado em: $07 \mathrm{dez}$. 2016.

CRAWFORD, A.W.; PINO, J.D.; BECKERLE, M.C. Biochemical and molecular characterization of the chicken cysteinerich protein, a developmentally regulated LIMdomain protein that is associated with the actin cytoskeleton. J. Cell Biol., v.124, p.117-127, 1994.

DAL BOSCO, A.; MUGNAI, C.; RUGGERI, S. et al. Fatty acid composition of meat and estimated indices of lipid metabolism in different poultry genotypes reared under organic system. Poult. Sci., v.91, p.2039-2045, 2012.

DIET, nutrition and the prevention of chronic diseases. Geneva: World Health Organization, 2003. 149p.

ELEROGLU, H.; YILDIRIM, A.; ISIKLI, N.D. et al. Comparison of meat quality and fatty acid profile in slow-growing chicken genotypes fed diets supplemented with Origanum vulgare or Melissa officinalis leaves under the organic system. Ital. J. Anim. Sci., v.12, p.396-403, 2013.

FERREIRA, D.F. Análises estatísticas por meio do Sisvar para Windows versão 4.0. In: REUNIÃO ANUAL DA REGIÃO BRASILEIRA DA SOCIEDADE INTERNACIONAL DE BIOMETRIA, 45., 2000, São Carlos. Anais... São Carlos: UFSCAR, 2000. p.255-258. (Programa e resumos).

FOLCH, J.; LEES, M.; SLOANE STANLEY, G.H. A simple method for isolation and purification of total lipids from animal tissues. $J$. Biol. Chem., v.226, p.479-503, 1957.

FRENCH, P.; STANTON, C.; LAWLESS, F. et al. Fatty acid composition, including conjugated linoleic acid, of intramuscular fat from steers offered grazed grass, grass silage, or concentrate based diets. J. Anim. Sci., v.78, p.2849-2855, 2000.

HARTMAN, L.; LAGO, R.C.A. Rapid preparation to fatty acids methyl esters. Lab. Pract., v.22, p.475-476, 1973.

JUMP, D.B.; DEPNER, C.M.; TRIPATHY, S. Omega-3 fatty acid supplementation and cardiovascular disease. J. Lipid Res., v.53, p.2525-2545, 2012. 
KOUBA, M.; ENSER, M.; WHITTINGTON, F.M. et al. Effect of a high linolenic acid diet on lipogenetic enzyme activities, fatty acid composition and meat quality in the growing pig. J. Anim. Sci., v.81, p.1967-1979, 2003.

KUÇUKYILMAZ, M.; BOZKURT, M.; ÇINAR, M. et al. Chemical composition, fatty acid profile and colour of broiler meat as affected by organic and conventional rearing systems. $S$. Afr. J. Anim. Sci., v.42, p.360-368, 2012.

LABORDE, F.L.; MANDELL, I.B.; TOSH, J.J. et al. Breed effects on growth performance, carcass characteristics, fatty acid composition, and palatability attributes in finishing steers. $J$. Anim. Sci., v.79, p.355-365, 2001.

LARA, L.J.C.; BAIÃO, N.C.; AGUILAR, C.A.L. et al. Rendimento composição e teor de ácidos graxos da carcaça de frangos de corte alimentados com diferentes fontes lipídicas. Arq. Bras. Med. Vet. Zootec., v.58, p.108-115, 2006.

METZ, P.A.M.; MENEZES, L.F.G.; SANTOS, A.P. et al. Perfil de ácidos graxos na carne de novilhos de diferentes idades e grupos genéticos terminados em confinamento. Rev. Bras. Zootec., v.38, p.523-531, 2009.

NASCIF, C.C.C.; GOMES, P.C.; ALBINO, L.F.T.; ROSTAGNO, H.S. Determinação dos valores energéticos de alguns óleos e gorduras para pintos de corte machos e fêmeas aos 21 dias de idade. Rev. Bras. Zootec., v.33, p.375-385, 2004.

NECESSIDADES nutricionales para avicultura: pollos de carne y aves de puesta. Madrid: Fundação Española para Del Desarrollo de La Nutrición Animal, 2008. 79p.

PERINI, J.A.L.; STEVANATO, F.B.; SARGI, S.C. et al. Ácidos graxos poli-insaturados n-3 e n-6: metabolismo em mamíferos e resposta imune. Rev. Nutr., v.23, p.1075-1086, 2010.
POURESLAMI, R.; RAES, K.; TURCHINI, G.M. et al. Effect of diet, sex and age on fatty acid metabolism in broiler chickens: n-3 and n-6 PUFA. Br. J. Nutrit., v.104, p.189-197, 2010.

QUARESMA, M.A.G.; PIMENTEL, F.B.; RIBEIRO, A.P. et al. Lipid and protein quality of common pheasant (Phasianus colchicus) reared in semi-extensive conditions. J. Food Compost. Anal., v.46, p.88-95, 2016.

RIBEIRO, P.A.P.; LOGATO, P.V.R.; PAULA, D.A.J. Efeito do uso de óleo na dieta sobre a lipogênese e o perfil lipídico de tilápias-do-Nilo. Rev. Bras. Zootec., v.37, p.1331-1337, 2008.

ROSTAGNO, H.S.; ALBINO, L.F.T.; DONZELE, J.L. et al. (Eds.). Tabelas brasileiras para aves e suínos: composição de alimentos e exigências nutricionais. Viçosa: UFV, 2011. $186 \mathrm{p}$.

SIRRI, F.; CASTELLINI, C.; BIANCHI, M. et al. Effect of fast, medium and slow-growing strains on meat quality of chickens reared under the organic farming method. Animal, v.5, p.312319, 2011.

SIRRI, F.; CASTELLINI, C.; RONCARATI, A. et al. Effect of feeding and genotype on the lipid profile of organic chicken meat. Eur. J. Lipid Sci. Technol., v.112, p.994-1002, 2010.

TANG, H.; GONG, Y.Z.; WU, C.X. et al. Variation of meat quality traits among five genotypes of chicken. Poult. Sci., v.8, p.22122218, 2009.

ULBRICHT, T.L.V.; SOUTHGATE, D.A.T. Coronary heart disease: seven dietary factors. Lancet, v.338, p.985-992, 1991. 